\title{
A NECESSIDADE DO ACASO: UM CONVITE AO DIÁLOGO FILOSÓFICO ${ }^{1}$
}

\author{
Lauro Frederico Barbosa da SILVEIRA ${ }^{2}$
}

- RESUMO: Um posicionamento filosófico realista que não coloque em dúvida a inteligibilidade do universo ao qual investiga e não se pretenda detentor de qualquer privilégio para alcançar a verdade admite a falibilidade de qualquer representação da realidade, não vendo motivo para fugir ao diálogo com aqueles que propõem explicações diferentes das suas, mesmo que por vezes com elas conflitantes.

- PALAVRAS-CHAVE: Realismo; diálogo; falibilismo.

Uma postura realista diante dos objetos da experiência parece ser aquela que vem sendo habitualmente assumida pelos investigadores dos fenômenos da natureza. Não parece, contudo, ser absolutamente necessário que estes investigadores, ao colocarem questões filosóficas, procurem para elas respostas necessariamente marcadas por um posicionamento realista. Em decorrência do nível de abstração em que se desenvolverá o pensamento filosófico, será possível àqueles investigadores, por exemplo, restringirem-se a só legitimamente discutir a linguagem do discurso, não lhes parecendo pertinente adentrarem o domínio dos fenômenos não-simbólicos a fim de investigá-los no nível ontológico.

Talvez fosse válido interpretar neste sentido a proposição de Wittgenstein (1987, p.204), engenheiro mecânico e arquiteto, de que os

\footnotetext{
1 Texto originalmente apresentado na Semana de Filosofia da PUC - SP, em setembro de 1995.

2 Departamento de Filosofia da Faculdade de Filosofia e Ciências - UNESP - 17525-900 - Marília $\mathrm{SP}-$ Brasil.
} 
problemas filosóficos se iniciam quando a linguagem entra em férias, ou "tem um momento de festa", como prefere traduzir a edição portuguesa: descompromissada do trabalho quotidiano e utilitário de representar as coisas, as pessoas e suas relações, quando não pode se dar ao luxo de radicalizar as questões e, muito menos, questionar sua própria capacidade representativa, a linguagem entraria em férias, ou em clima de festa, e exporia sem peias suas próprias contradições.

A possibilidade de assim proceder, e de proceder à elaboração de discursos e de poemas de excepcional qualidade, é que não tornaria ridiculamente tautológico o questionar cético, já que freqüentemente põe questões previamente sabidas sem resposta.

O mesmo nível de abstração que possibilita que do seio da experiência diária, assim como do seio da experiência científica e tecnológica, produza-se um elaborar filosófico que se legitime exclusivamente na investigação do discurso, permite também que um posicionamento filosófico tenha lugar, assumindo como problema seu, inseparável do da própria construção discursiva, o do estatuto de realidade daquilo que não se duvida na experiência diária ou na controlada experiência científica e tecnológica.

A liberdade da razão parece ser tal que, ao colocar questões filosóficas, poderá estar satisfazendo às suas exigências mesmo tomando posições antagônicas. Considerar esta diversidade que resiste a todas as tentativas de suplantação ou de superação convida a que a ela, talvez, se aplique o princípio de complementaridade, que tão sabiamente sugeria Niels Bohr diante dos impasses vividos pela investigação no domínio da física atômica. ${ }^{3}$

O mal-estar gerado pela aceitação do convívio insuperável das posições contraditórias não é desprezível ao se considerar que as filosofias querem se fazer respeitar quanto a uma certa exclusividade na capacidade, senão mais verdadeira ao menos mais feliz, de abordar o mais íntimo da realidade, nem que seja sob a forma de um jogo.

A natureza irredutivamente polêmica do questionar filosófico denunciada, como todos sabemos, no texto de Guéroult (1956, p.45-68) parece mostrar a radicalidade daquele mal-estar mas, talvez, venha reforçar a conveniência de que se tente explorar um pouco a aplicabilidade daquele princípio, também no domínio fílosófico.

3 Quanto à apresentação crítica, bastante recente e completa, do princípio de complementaridade, originalmente proposto por Niels Bohr, consultar Paty (1995). 
Certamente existem posições filosóficas que mais facilmente ou que com menos dificuldade acolheriam a pertinência de um tal princípio sem se verem com isso frustradas em seus critérios e objetivos.

Uma filosofia da diferença e da dispersão relativizaria, irônica ou humoristicamente, a própria busca de um discurso fundante da verdade da realidade, embora sob o risco de se ver ela mesma desacreditada: médico, cura-te a ti mesmo!

Uma outra assumiria a própria contradição como a razão necessitante e instauraria a verdade sobre e por meio destas próprias contradições. O risco que correria é o de desacreditar de quem assim não procedesse, de voltar a se achar exclusiva e, conseqüentemente, em ser contraditada e ameaçada em seu domínio por quem dela difira.

Haveria, certamente, a filosofia que veria nesta tentativa mais um esforço vão de alcançar racionalmente a verdade num domínio outro que o da consistência do discurso, daquele em que atua o senso comum ou em que trabalham as ciências empíricas. Sua opção talvez fosse a de renunciar a seu próprio discurso e, ou continuar a ouvir o dos outros, ou abandonar a conversação.

Poderia, mesmo, ocorrer um posicionamento eclético que acolhesse como verdadeiras, num discurso único, proposições originárias de diversas fontes sem questionar sua compatibilidade. Neste caso, parece, o recurso ao próprio princípio de complementaridade perderia sua razão de ser, pois a especificidade das diversas abordagens não mais estaria sendo levada em questão.

Uma posição filosófica realista que não pretendesse fundamentar seu discurso imediatamente numa representação intuitiva mas que lhe reconhecesse um caráter eminentemente conjectural conseguiria, não sem enfrentar desafios e dificuldades, compartilhar a busca da verdade com teorias a ela irredutíveis, dado ao reconhecimento que tem de sua própria falibilidade.

Se o amor ao objeto for mais forte que sua necessidade de poder, será possível a esta posição filosófica conviver com posicionamentos que lhe sejam antagônicos. Continuaria capaz de trazer contribuições para uma maior razoabilidade do real sem precisar renunciar às exigências de seu próprio questionar original.

O reconhecimento do caráter intrinsecamente falível de suas proposições faria que ela não fosse levada a reclamar para si uma exclusividade ou uma maior perfeição, que lhe dificultariam o diálogo e lhe impossibilitariam avançar em seu próprio questionamento, mesmo que não se fizessem presentes, no momento, filosofias a ela antagônicas.

Embora crítico dos posicionamentos filosóficos dogmáticos, freqüentemente caudatários de concepções teológicas acerca das realidades 
últimas e, mais em geral, de uma atitude nominalista que perpassa as mais diversas tendências filosóficas e que desacredita da presença de um genuíno modo geral de ser, da ordem do pensamento, na trama da realidade, Peirce declara adotar uma estratégia profundamente dialogante para levar adiante seu questionamento filosófico.

Num texto bastante conhecido, datado de $1897,{ }^{4}$ quando já confinado em Milford, Pensilvânia. e passando as mais extremas necessidades, Peirce resolve escrever como prefácio para um pretenso livro de filosofia um texto autobiográfico em tom de quase um testamento. Não podia avaliar, com certeza, quanto ainda produziria e quão original seria esta futura produção.

A certa altura, como sempre foi de seu estilo, deixa lavrada uma declaração lapidar. Nesta, caracteriza todo seu labor filosófico nos seguintes termos:

\begin{abstract}
... minha filosofia pode ser descrita como a tentativa de um físico de conjecturar sobre a constituição do universo do modo como os métodos científicos podem permitir, com a ajuda de tudo que vem sendo feito pelos filósofos que the precederam. Sustentarei minhas proposições nos argumentos dos quais puder dispor. Não se deve pensar em prova demonstrativa, as demonstrações dos metafísicos são meras aparências (são como o clarão da lua, diz o texto original). $\mathrm{O}$ melhor que pode ser feito é produzir uma hipótese, não destituída de toda a similitude, na linha geral do desenvolver das idéias científicas, capaz de ser verificada ou refutada por futuros observadores. (Peirce, 1931-1974, v.1, § 7)
\end{abstract}

Diante da grandeza infinita do objeto a ser investigado e pelo fato mesmo deste ultrapassar os limites do que pode a física procurar explicar, o pesquisador é levado a penetrar no domínio filosófico e lançar alguma hipótese que possa talvez responder à razão em sua necessidade de penetrar no âmbito daquele objeto, no qual ela espera encontrar sua máxima plenitude.

Neste domínio cabe, em primeiro lugar, recorrer àqueles que no passado longínquo ou recente procuraram empreender semelhante investigação. Os filósofos serão consultados, e conforme mostra a obra peirceana e relata este mesmo texto autobiográfico, a consulta será feita com grande atenção, por longo tempo e, muitas vezes, reiteradamente, mesmo daqueles filósofos com os quais o autor confessa não manter qualquer simpatia e de cujo pensamento diverge com freqüência.

4 PEIRCE, C. S. Collected papers of Charles S. Peirce. HARTSHORNE, C., WEISS, P. (Ed.) Cambridge, MA: The Belknap Press of Harvard University, 1931-1974. v.1, 2. 
Para levar a cabo tal empreendimento, deve-se proceder cientificamente, e isto significa para Peirce seguir com a máxima humildade um método que, devido às próprias características do objeto a ser conhecido, aconselhará que se adotem determinadas estratégias.

No caso agora em consideração, o objeto seria o próprio cosmos, o todo metafisicamente ordenado, pois certamente é esta a conotação aqui conferida a universo. Deve, então, ser atribuída à construção de hipóteses o máximo relevo seguidas de um desdobrar de conseqüências direta ou indiretamente observáveis que possam ser delas deduzidas. Construirse-á, pode-se supor, um símbolo marcadamente icônico, ou ícone simbolóide como pode-se ler em outro texto na obra peirceana, que se assemelhando ao próprio universo, objeto da investigação, permita à mente observá-lo e sobre ele cogitar.

Aos futuros pesquisadores caberá submeter ao teste da experiência a validade de se adotar como programa de conduta as proposições encaminhadas, considerando-se que esta dimensão programática das representações teóricas constitui, para Peirce, a verdade destas proposições.

Em domínios desta natureza fica bastante claro que o motivo da investigação científica é a admiração, uma vez que nenhuma utilidade pode aí ser buscada por si mesma. Quanto mais o objeto for geral, mais se exigirá do método que ele adote um caráter eminentemente conjectural, tomando por base uma forma poética a ser desdobrada rigorosamente, segundo as exigências lógicas, nas relações conceituais nela implicadas.

Será, finalmente, no domínio ético de confronto com o objeto procurado que a verdade da teoria será verificada, mesmo que tal confronto só se perfaça plenamente de modo tendencial, numa relação sempre futura.

É a similitude possível e sempre aproximada do signo com o objeto que constantemente prevalecerá e tal signo, por mais que conceitualmente se desenvolva, somente servirá de guia, de sugestão, para que uma mente tomada de amor pelo objeto siga ao seu encontro.

Não se tratará, jamais, em matéria desta natureza de se obter uma demonstração irrefutável da verdade da representação. Ao se procurar representar em domínio metafísico, sabe-se perfeitamente que estarão sendo elaboradas hipóteses dotadas de caráter indecidível quanto à verdade ou falsidade de suas conclusões. Daí decorre, a priori, a vacuidadade das demonstrações em senso estrito, pretendidas por qualquer metafísico.

Não se estará, contudo, penetrando no domínio do irracional ao se teorizar metafisicamente sobre o universo, pois a razão não se satisfaz somente com demonstrações exclusivas e irrefutáveis, mas se a razão é lógica ela o é por ser ética, e se confundiria com uma razão do mero dever se não fosse originariamente poética. O belo e o bom agradam e movem a razão, bastando a ela, por vezes, uma representação eminente- 
mente icônica, marcadamente analógica, do objeto para fazer com que o projete como uma realização específica do ser, encontrando, deste modo, uma fundamentação para a esperança de alcançá-lo no futuro.

O cuidado em conservar e aprimorar constantemente a forma que se encontra em sua própria essência, como campo de experimentação que pretende ser, leva o pensamento a procurar uma coerência cada vez mais bem integrada.

Ao evitar, pois, comprometer a consistência conceitual e a rigorosa dedutibilidade das conclusões com qualquer confusão eclética, não se acha o pensamento impedido de procurar em construções diferentes da que no momento empreende, sugestões e ensinamentos que lhe facilitem o caminho e lhe ajudem a avaliar o poder explicativo e os limites dos procedimentos que, talvez, pretendesse adotar.

Ao contrário, esta procura se lhe impõe, preferencialmente daqueles posicionamentos que sob muitos aspectos com ele antagonizam, já que é mais provável que possam guardar perante ele um maior grau de independência e uma maior isenção para avaliar seus méritos.

É deste modo, por exemplo, que na carta a Lady Victoria Welby, de 12 de outubro de 1904, Peirce vê como uma confirmação indutiva da pertinência de se estabelecer uma tríade categorial para a representação do universo fenomênico a triadicidade das categorias kantianas em cada um dos quatro tópicos em que se distribuem e a tríade essencial à dialética hegeliana (cf. Peirce, 1958, v.8, §329).

A busca da verdade que se supõe sincera faz com que, independentemente do ponto de partida adotado - diríamos, de sua poesia originária -, as teorias sirvam umas para as outras de um campo possível, e impiedosamente privilegiado, de avaliação.

A uma visão necessitarista de universo seguir-se-ia quase necessariamente uma visão necessitarista de ciência, se esta pretendesse adequadamente representá-lo.

Num universo mecanicamente organizado, o progresso da investigação científica e da representação filosófica só poderia vir a ocorrer devido ao grau de ignorância e de imperfeição de que estas últimas estariam afetadas.

Um universo deterministicamente constituído somente daria lugar a uma única forma legítima de representação, caso ainda houvesse alguma forma legítima e não simplesmente ilusória que pudesse representá-lo.

Certamente, e isto os estudos de Ivo Assad Ibri $(1992,1994)$ deixam muito claro, haveria radical incompatibilidade entre um universo determinado exclusivamente pelo jogo de ação e reação e as formas de representação generalizantes próprias do pensamento.

Mesmo generalizações imperfeitas, produzidas pela repetição de experimentos e que, por mais artificiosas que fossem, dificilmente pode- 
riam pretender fornecer uma explicação plausível das originais hipóteses científicas e filosóficas ou das grandes produções artísticas, trazem consigo um elemento a mais do que o mero somatório de fatos.

Conviria, mesmo, lembrar que somar fatos já é irredutível aos próprios fatos e que uma máquina de Turing - modelo máximo da construção determinista - não computa, que saibamos, a função sucessor, base para qualquer soma. Esta tem de lhe ser fornecida no programa original.

Seria, contudo, somente diante de um universo estritamente determinista, pois nem mesmo diante da Palavra Revelada este caso se daria, que as teorias poderiam exigir para si total exclusividade na capacidade de representar verdadeiramente seu objeto. Somente diante de uma total ausência de alternativas possíveis é que esta exclusividade poderia ocorrer plenamente.

O estrito determinismo, aliás, não dá lugar a qualquer forma de conhecimento. Somente, pois, a presença do acaso e da espontaneidade confere as condições necessárias para que estas formas tenham lugar.

Somente um universo que, de algum modo, conhecesse o crescimento e a evolução poderia incluir o pensamento em todas ou em qualquer uma de suas manifestações entre os seus elementos integrantes, já que pensar é crescer, generalizar-se e diversificar-se.

Quanto mais o universo fosse permeado por processos evolutivos, mais lugar daria aos fenômenos psíquicos em sua própria constituição. Neste universo as determinações seriam todas relativas, quer eficientemente ao produzir transformações na existência, quer teleologicamente ao incrementar o desenvolvimento ideal das formas. E a esta última espécie de causação caberia a precedência sobre a primeira.

Independentemente do grau de avanço e de precisão do conhecimento de seu objeto, muito em especial quando este objeto é o universo em sua dimensão metafísica, a representação que se obtém será sempre de caráter conjectural e sua adequação ao objeto será sempre aproximada. A razão última desta conclusão se encontraria no fato de não só o conhecimento, mas o próprio objeto, serem essencialmente atravessados pela espontaneidade do acaso e estarem em constante e genuína evolução.

A presença necessária do acaso, sem a qual o universo e o conhecimento não teriam lugar, radicalmente impede que qualquer teoria e, em especial, qualquer filosofia possa pretender, sob o risco de se tornar instrumento de opressão ou sujeito de derrisão, alcançar a posse exclusiva da verdade.

Muito especialmente uma posição filosófica de cunho realista, que não invoque para a razão e, a fortiori, para si, qualquer acesso privilegiado e não mediatizado ao real, necessita, sem escamotear suas diferenças 
com demais doutrinas, transformá-las em ocasião propícia para que este aperfeiçoamento se efetive.

Pela necessidade decorrente da preservação de sua coerência interior, uma posição filosófica que pretenda, em última instância, medir-se por um objeto em constante evolução e que dela não depende em seu modo de ser só pode reconhecer-se eminentemente falível e, portanto, constantemente aperfeiçoável para a ele se adequar. Não pode, portanto, reclamar qualquer direito a uma posse exclusiva ou preferencial da verdade e, portanto, não tem motivos para frustrar-se a um amplo e irrestrito diálogo com todas as demais filosofias. Num universo de espontaneidade e liberdade, quanto mais vozes levantarem cantos, maior será o gozo de se encontrar em sintonia com a busca comum da verdade.

SILVEIRA, L. F. B. da. The necessity of chance: an invitation to philosophical dialogue. Trans/Form/Ação (São Paulo), v.20, p.95-101, 1997.

- ABSTRACT: A realistic philosophy that does not put in question the intelligibility of the universe it investigate and does not intend to be itself the owner of any privilege in the search of the Truth, admits the fallibility of all kind of representations of the reality. Then it does not see any reason for eviting the dialogue with those who propose different explanations from its own, although sometimes it may be found a true conflict between them.

- KEYWORDS: Realism; dialogue; fallibilism.

\section{Referências bibliográficas}

GUÉROULT, M. Le problème de la légitimité de l'histoire de la philosophie. In: CASTELLI, R. Philosophie de l'Histoire de la Philosophie. Paris: Vrin, 1956.

IBRI, I. A. Kosmos noetós: a arquitetura metafísica de Charles S. Peirce. São Paulo: Holón, Perspectiva, 1992.

Kosmos poietikós: criação e descoberta da filosofia de Charles S. Peirce. São Paulo, 1994. Tese (Doutorado) - Universidade de São Paulo.

PATY, M. A matéria roubada. São Paulo: Edusp, 1995.

PEIRCE, C. S. Collected Papers of Charles S. Peirce. Burks, P. W. (Ed.). Cambridge, MA: The Harvard University Press, 1958. V.8.

PEIRCE, C. S. Collected Papers of Charles Peirce. HARTSHORNE, C. WEISS, P. Cambridge, MA: The Belknap Press of Havard University, 1931-1974, v.1, 2.

WITTGENSTEIN, L. Investigações filosóficas. In: . Tratado lógico-filosófico/Investigações Filosóficas. Lisboa: Gulbenkian, 1987. § 38. 